\title{
Pharmacokinetic Concentration Original Result Unit
}

National Cancer Institute

\section{Source}

National Cancer Institute. Pharmacokinetic Concentration Original Result Unit. NCI

Thesaurus. Code C87962.

The unit of measure first specified in the pharmacokinetic concentration assessment. 